\title{
$R_{\text {esearch }} P_{\text {aper }} \longrightarrow$ FOOD SCIENCE \\ Efficacy and enrichment of the products by using mushroom
} Volume 9 | Issue 2 | October, 2018 | 294-297

DOI : $10.15740 / \mathrm{HAS} / \mathrm{FSRJ} / 9.2 / 294-297$

\author{
Kiran Agrahari and Priya Jaiswal
}

\begin{abstract}
The objective of present investigation was efficacy and enrichment of the products by using mushroom. Mushroom have a creamy flavour, soft texture and are easy to digest, mushroom are a high source of nutrients like moisture, energy, protein, fat, carbohydrate, minerals, calcium, iron, phosphorus, potassium, sodium, magnesium, thiamin, riboflavin and fibre. They are also a very filling food. Mushroom are considersd useful in defending against several chronic, age-related diseases, including heart disease, cancer, diabetes and obesity and lower the high cholesterol levels and protect against heart disease. The developed products were given to the panel of 10 judges, products were tested for flavour and taste, body and texture, colour and appearance, overall acceptability. The Organoleptic evaluation of products was done by using score card method (9-point hedonic scale). The result of mushroom based products i.e. mushroom cutlet and mushroom uttapam $\left(\mathrm{T}_{0}\right)$ and $\left(\mathrm{T}_{1}\right)$ was best in all treatments in case of all sensory attributes. The overall acceptability of experimental $\left(T_{1}\right)$ mushroom cutlet and mushroom uttapam were 9.0, 8.4, respectively.
\end{abstract}

Key Words : Mushroom, Efficacy, Enrichment, Age-related diseases, Heart diseases

How to cite this article : Agrahari, Kiran and Jaiswal, Priya (2018). Efficacy and enrichment of the products by using mushroom. Food Sci. Res. J., 9(2): 294-297, DOI : 10.15740/HAS/FSRJ/9.2/294-297. Copyright@ 2018: Hind Agri-Horticultural Society. 